\title{
Successful Prevention of HIV Transmission From Mother to Infant in Brazil Using a Multidisciplinary Team Approach
}

\author{
Susie A. Nogueira, Thalita Abreu, Ricardo Oliveira, \\ Lúcia Araújo, Tomaz Costa, Miriam Andrade, \\ M. Fátima Garcia Psic, Machado, Káris Rodrigues, \\ Elizabeth Regina Mercadante, Iraína Fernandes, \\ M.Conceição Sapia and John S. Lambert
}

\author{
Federal University of Rio de Janeiro, \\ Brazil; Fogarty International AIDS \\ Training Program, University of \\ Maryland - Institute of Human Virology, \\ Baltimore, Maryland, USA
}

Objectives: To determine the HIV vertical transmission rate (VTR) and associated risk factors by use of zidovudine and infant care education in Brazil. Methods: Since 1995, a prospective cohort of HIV infected pregnant women has been followed at the Federal University of Rio de Janeiro. A multidisciplinary team was established to implement the best available strategy to prevent maternal-infant HIV transmission. Patients with AIDS or low $\mathrm{CD}_{4}$ and high viral load received anti-retroviral drugs in addition to zidovudine. Children were considered infected if they had 2 positive PCR-RNA tests between 1 and 4 months of age, or were HIV antibody positive after 18 months. Education regarding infant treatment and use of formula instead of breast feeding was provided. Results: Between 1995 and August, 2000, HIV status was determined for 145 infants. Compliance with intra-partum treatment, infant treatment and use of formula was $88.2 \%$. Intra-partum zidovudine treatment was completed in $134 / 145(92.6 \%)$ of patients; $88.1 \%$ had rupture of membranes < 4 hours; $85.4 \%$ of mothers were asymptomatic. The mean $\mathrm{CD}_{4}$ count was 428.4 cells and mean viral load 39,050 copies. HIV vertical transmission rate was $4 / 145(2.75 \%$; CI: $0.1 \%$ $5.4 \%$ ). The only risk factor significantly associated with transmission was a failure to use zidovudine intra-partum in 2 of the 4 mothers (50\% versus $6.4 \%$ in non-transmitting mothers). A trend toward low $\mathrm{CD}_{4}$ and high viral load at entry, and rupture of membranes > 4 hours were associated with increased HIV transmission. Conclusion: HIV vertical transmission in Brazil was reduced to a level similar to other countries with the most effective prevention programs using a multidisciplinary team approach. A high level of compliance for use of anti-retroviral drugs, the provision of health education to mothers, and use of formula for all exposed infants.

Key Words: Brazil, HIV, prevention, perinatal transmission, zidovudine.

Received on 15 January 2001; revised 25 March 2001.

Address for correspondence: Dr. Susie Andries Nogueira Serviço de Doenças Infecciosas e Parasitárias $-5^{\circ}$ andar Hospital Universitário Clementino Fraga Filho, Universidade Federal do Rio de Janeiro. Av. Brigadeiro Trompovski s $/ \mathrm{n}^{\circ}$. Ilha do Fundão. Rio de Janeiro, RJ, Brazil, Zip Code: 21941590. Phone: (21) 590-5252. Fax: (21) 590-5422. Email: susie@hucff.ufrj.br

The Brazilian Journal of Infectious Diseases 2001;5(2):78-86 (C) 2001 by The Brazilian Journal of Infectious Diseases and Contexto Publishing. All rights reserved. $1413-8670$
The first case of pediatric AIDS secondary to a blood transfusion was reported to the Ministry of Health of Brazil in 1983. During the next 4 years, a total of 190 cases were reported, with $70.5 \%$ secondary to blood products transfusion. More recently, in Brazil, risk factors for HIV acquisition has shifted from homosexual/bisexual sexual behavior and blood products contamination, to heterosexual contact. Currently, heterosexual transmission is the predominant mode of HIV transmission, resulting in a rapid increase in HIV infection among women, mostly of childbearing 
age. In parallel, there has been an increase in the number of perinatally infected children and, as of June, 2000, 6,750 cases of AIDS in Brazilian children were reported.

Safeguards for the blood supply in Brazil have been significantly improved since 1986, especially in metropolitan areas, resulting in a significant drop in transfusion acquired HIV infection. Currently, perinatal transmission is responsible for $90.6 \%$ of all reported pediatric AIDS cases in Brazil [1].

Following the results of PACTG 076 [2], the efficacy of zidovudine (ZDV) prophylaxis in reducing HIV transmission from mother to infant has been demonstrated in many studies [3-5]. This regimen, in parallel with routine HIV testing of all pregnant women, is becoming the standard of care in developed countries $[6,7]$. Concerns have been raised regarding the implementation of ZDV prophylaxis in many developing countries, where $90 \%$ of worldwide HIV infection in children is concentrated, primarily because of cost and complexity of HIV testing, zidovudine treatment and health education programs. A number of placebo controlled trials were designed by investigators in developed countries using abbreviated courses of ZDV in Asia and Africa, with the objective of finding simpler and less expensive regimens of antiretroviral treatments that might effectively interrupt HIV vertical transmission $[8,9]$. Much criticism was raised against such placebo trials because of the double standard of care provided to HIV infected pregnant women [10].

We believe that prevention of mother to infant HIV transmission must be an urgent public health priority, since effective therapies are currently available. The problem in developing countries is one of access to care, and affordability of effective preventive therapies. Developing a strategy to implement such therapies is an ethical imperative. A number of studies have shown that reducing the number of pediatric HIV infection cases through a perinatal preventive approach is costeffective, so strategies to achieve this goal must be prioritized and implemented with great haste $[11,12]$. In Brazil, oral ZDV is provided free of charge to HIV infected pregnant women (intravenous ZDV has been available since 1996).
We believe that with adequate training of health professionals, implementation of very effective strategies for reducing vertical transmission of HIV is possible. To achieve this, a program for the integrated care of HIV infected pregnant women was established at the Federal University of Rio de Janeiro. Our program has two main objectives: 1) to administer the zidovudine to pregnant women identified as HIV infected; and 2) to train health care workers on strategies to prevent HIV transmission from mother to infant, and to disseminate this information to other hospitals. In addition to medical care, our program emphasizes the social, emotional, cultural and economic impact of being an HIV positive pregnant woman [13]. These issues differ from country to country, and must be dealt with in a country specific manner as a part of routine medical care. Our program has developed a multidisciplinary team approach that we have found optimal for implementing successful prophylactic and/or therapeutic intervention for HIV infected patients.

Here, we present the results of a prospective study of mother to infant HIV transmission following use of an antiretroviral drug/health education program in a cohort of HIV infected pregnant women in Rio de Janeiro. We also present an analysis of biological and obstetrical risk factors associated with mother to infant transmission of HIV.

\section{Materials and Methods}

Subjects and Resources: In the second half of 1995, a multidisciplinary team was established at Federal University of Rio de Janeiro to implement an integrated program of medical treatment and education. Our strategy was to teach health professionals to implement the program, and to provide them with the tools to develop an infrastructure and find resources necessary to reduce vertical transmission of HIV-1. The implementing team consisted of infectious diseases specialists, obstetricians, pediatricians, psychologists, nurses, and social workers. A non-governmental organization (NGO) was established by members of the implementation team to provide non-medical support 
for the program; for example, to provide formula to all exposed infants. Purchases were made with donations and membership fees.

At the pre-natal clinic of Instituto de Puericultura e Pediatria Matargão Gesteira (the Pediatric Institute of the Federal University of Rio de Janeiro, Brazil), all pregnant women diagnosed with HIV, and their at risk and HIV infected children, are evaluated and treated. All mothers and their children are seen during the same clinic session by the multidisciplinary team. Nurses and psychologists conduct discussion groups with patients in the clinic waiting room in order to address the medical, social, psychological and cultural issues relevant to the patients. Patients are instructed not to breastfeed, and how to obtain formula and prepare it properly [13].

Interventions: All infected pregnant women were offered zidovudine treatment and, after consent was given, were started as early as 14 of gestation. If intravenous ZDV was not available, oral ZDV was administered during labor. For women with severe immunosuppression or those with high viral loads, other antiretrovirals, most commonly 3TC, were added to the regimen. In those women who were already taking anti-retrovirals responding well, their combined antiretroviral therapeutic regimens were continued in accordance with guidelines from the Brazilian Ministry of Health (STD/ AIDS Division) [14, 15].

When intravenous ZDV was not available, oral ZDV was administered $300 \mathrm{mg}$ every 3 hours during labor. Women with $\mathrm{CD}_{4}$ counts of $<200 / \mathrm{mm}^{3}$ had SMZ/TMP added to their treatment 3 times weekly. Iron supplements were given to anemic patients, and evaluation and treatment of vaginal infections and/ or STDs were provided to all women. Most patients who underwent Caesarean section received 1 dose of prophylactic antibiotics (most commonly Cephalothin) following clamping of the umbilical cord. All exposed infants received a monthly supply of milk formula, free of charge, during the first year of life, or for a longer period if he/she was confirmed as HIV infected.
Laboratory methods: All pregnant women referred to our Program were re-tested for HIV by ELISA and Western Blot assays (Biokit and Organon kits). Those with 2 positive ELISA tests and 1 positive Western blot test were enrolled in our study. The following criteria were used for diagnosis of HIV infection in perinatally exposed children: HIV Immunoglobulin (IgG) detected by 2 ELISA tests and Western Blot tests persisting beyond 18 months of age; and/or 2 PCR RNA (NASBA) evaluations performed at 1 month and at 4 or more months of life $[16,17]$.

$\mathrm{CD}_{4}$ cell count measurements were performed using flow cytometry and viral load (RNA PCR) measurements using the NASBA assay (Organon); all tests were performed at the laboratories of the Hospital Universitário Clementino Fraga Filho/UFRJ, one of the reference laboratories for the city of Rio de Janeiro, licensed by the Brazilian Ministry of Health) [7,18] .

Statistical analysis. The data were collected from hospital medical charts and from the standardized forms completed at each clinic visit [19], and analyzed using Epi info 6(CDC). Simple frequencies were initially performed on all variables. Categorical data were analyzed with Chi square (Yates correction or Fisher exact test, whenever indicated). Means were compared with Student T test, and statistical significance was set at a $5 \%$ level [p $<0.05]$.

\section{Results}

Between 1996, and August, 2000, 177 patients had given birth and 145 infants had their HIV status confirmed. Table 1 summarizes patient demographics. Maternal age ranged from 16 to 43 years old (mean: 26.1, SD: 5.8); most of the women were housewives (59.1\%); among the others, $80 \%$ had no skilled job and had a low family income (70\% earned less than 300 US\$ dollars per month). Of the study patients, $162(91.3 \%)$ probably acquired HIV infection through heterosexual contact; $8(4.5 \%)$ from blood transfusions; and $7(3.9 \%)$ reported intravenous drug use. Data gathered from the patients indicated that $27.6 \%$ contracted a STD previously or during the current 
pregnancy, with human papillomavirus infection (HPV) (13.82\%) and syphilis (8.3\%) most frequently reported. On entry, $85.4 \%(152 / 177)$ of the enrolled patients were asymptomatic with a mean $\mathrm{CD}_{4}$ count of 428.4 cells/ $\mathrm{mm}^{3}$; median 400 and SD: 231.4; and mean viral load 39,050 copies/ml, median: 7,100 with a SD of 78,281.

During pregnancy, 9 women developed opportunistic infections: oral/esophageal candidiasis (5), disseminated herpes simplex virus infection(1), localized herpes zoster infection (2), Pneumocyctis carinii pneumonia (1), cerebral toxoplasmosis (1), and tuberculosis (2). Pregnancy complications consisted of pre-eclampsia in 5/123 (4.6\%); although data was not comprehensively collected on other infections, upper respiratory bacterial infections including sinusitis and bronchitis were common, and vaginal candidiasis was frequently reported.

The mean gestational age at which ZDV was started was 23.1 weeks, median 26 weeks, Sd: 10.8 weeks, range 0 to 39 weeks. Regarding administration of therapy, $88.2 \%(152 / 177)$ received all 3 components of the drug; $41.2 \%$ (73 patients) also received other antiretrovirals (54 received 3TC, and 7 received protease inhibitors); 7.4.\% (13/176) failed to receive the intra-partum component of the drug, primarily because of late arrival to the maternity unit. Generally, antiretroviral therapy was well-tolerated; 2 patients required blood transfusions to treat anemia (both had $<300 \mathrm{CD}_{4}$ cells/ml), and ZDV was successfully continued in both. One patient, who had been on AZT/ddI prior to pregnancy, was found to have an elevated blood amylase level in the last month of pregnancy, and ddI was changed to 3TC. All newborn infants received ZDV syrup for 6 weeks, except 3 , and mothers were provided with formula as a substitute for breast milk; 2 were also breast fed during the first week of life despite counselling against it: 1 patient had psychiatric problems and the second feared her family would discover her HIV status if she did not breast feed her child. One child was born with a genetic syndrome (Cornelia de Lange syndrome) not related to antiretroviral treatment (mother began ZDV after 14 weeks of pregnancy). Three children were lost to follow up, and 2 infants died: one at the age of 2 months with fulminant meningococcal infection, and the second at 3 months due to pneumonia; in both cases, their HIV status had not yet been ascertained.

Mean gestational age at delivery was 38.8 weeks (SD: 1.67$)$ with a $6.8 \%$ premature birth rate $(<37$ weeks gestation); $49.7 \%$ (88/177) of the patients had vaginal delivery, and $51.41 \%$ (91/177) had Caesarean section that was elective in 49 patients $(27.6 \%$ of all births); $88.1 \%$ (156/177) had rupture of membranes for less than 4 hours. Mean birth weight was 3,137 gm, median 3,157 gm, SD: 567gm.; 21 (11.7\%) babies weighed $<2,500 \mathrm{gm}$ at birth; 4 required intensive care treatment (for prematurity) and all survived; all of them are uninfected.

One hundred forty-three mothers delivered 145 infants including 2 sets of twins, both of whom are uninfected. The vertical transmission rate in 145 children was 4/145 (2.75\%) (CI: 0.1-5.4). Data about these four infants are recorded in Tables 2 and 3. If the two infants who died are presumed to have been infected with HIV (no confirmatory tests were performed), the vertical transmission rate is $4.13 \%$ (CI:0.8-7.1). However, meningococcal disease is hyperendemic in Rio de Janeiro city, and a common cause of infant mortality in normal children. In the infant who died of pneumonia, we cannot exclude the possibility of Pneumocystis carinii; the death occurred in another hospital and the infant was not taking prophylatic SMZ/ TMP for primary prophylaxis as is routine in our program [20].

\section{Discussion}

Demographics of the women enrolled in our project revealed that they were of lower socio-economic levels, and that most acquired their HIV infection from heterosexual partners; intravenous drug use was an infrequent risk factor for these women, which may partly explain their high compliance with integrated prenatal care. In São Paulo State, drug use was a more common risk factor, similar to many female cohorts described in the USA [21, 22]. The AIDS epidemic in Brazil has changed significantly in the last decade, and 
Table 1. Characteristics of enrolled HIV infected women

\begin{tabular}{ll}
\hline Age (means and SD) & 26.1 years (SD:5.8) \\
Income of family (minimal wage) & $3.3(\$ 276,8 \mathrm{US} /$ month) \\
Profession & $59.1 \%$ house wives \\
Heterosexual transmission & $91.6 \%$ \\
HIV asymptomatic disease & $86 \%$ \\
CD count (means and SD) & 428.4 cell/ml(SD:231.4) \\
Viral load at entry (means and SD) & 29,050 copies RNA/ml (SD:78,281) \\
Previous/ present STD & $27.3 \%$ \\
Syphilis & $8.3 \%$ \\
Gestational age at start of 076 (means/Sd) & $23.1(\mathrm{Sd}: 10.8)$ weeks \\
\hline
\end{tabular}

Table 2. Comparison between transmitting $(n=4)$ and non-transmitting $(n=87)$ mothers

\begin{tabular}{lccc}
\hline Parameter & Transmitting & Non-transmitting & p value \\
\hline CD $_{4}$ at entry (means and SD) cell/ml & 270.5 (SD:99.37) & 438 (SD: 234.4) & 0.10 \\
Presence of symptoms/signs of AIDS & 0 & $20 / 177$ & 0.20 \\
STD & 0 & $32 / 136$ & 0.20 \\
Viral load at entry (means and SD) copies/ml & 60,472 (SD:91,478) & $26,844($ SD:83,247) & 0.30 \\
Incomplete 076 regimen & $2 / 4$ & $13 / 139$ & 0.05 \\
Mean gestational age at ZDV Start (weeks) & 29.7 & 22.3 & 0.15 \\
Mean gestational age at delivery (weeks) & 38.7 & 38.9 & 0.80 \\
Mode of delivery: & & & \\
Vaginal & 2 & $2 / 71$ & 0.20 \\
Emergency C-section & 2 & $2 / 68$ & 0.60 \\
Elective C-section & 0 & 38 & - \\
Rupture of membranes $>$ 4hrs & $2 / 4$ & $17 / 139$ & 0.08 \\
Mean birth weight-gm & 3352 & 3155 & 0.70 \\
Other ARV besides ZDV & $2 / 4$ & $51 / 138$ & 0.60 \\
\hline
\end{tabular}

Table 3. Characteristics of the four HIV infected infants

\begin{tabular}{|c|c|c|c|c|}
\hline Patients & 1 & 2 & 3 & 4 \\
\hline Maternal $\mathrm{CD}_{4}$ & $234 \mathrm{cell} / \mathrm{ml}$ & 164 cell $/ \mathrm{ml}$ & $284 \mathrm{cell} / \mathrm{ml}$ & $400 \mathrm{cell} / \mathrm{ml}$ \\
\hline Maternal plasma viral load & 790 copies $/ \mathrm{ml}$ & $\begin{array}{l}195.000 \\
\text { copies/ml }\end{array}$ & 5,100 copies $/ \mathrm{ml}$ & 41,000 copies $/ \mathrm{m}$ \\
\hline Maternal AIDS & NO & NO & $\mathrm{NO}$ & $\mathrm{NO}$ \\
\hline Time $Z D^{1}$ started in pregnancy & 35 & 31 & 31 & 21 \\
\hline Other $\mathrm{ART}^{2}$ treatment & $\mathrm{NO}$ & YES (3TC) & YES (3TC) & $\mathrm{NO}$ \\
\hline 3 components of 076 & YES & YES & $\begin{array}{l}\text { NO (irregular } \\
\text { use last month } \\
\text { of pregnancy) }\end{array}$ & $\begin{array}{l}\text { NO (lack of } \\
\text { intra-partum } \\
\text { component) }\end{array}$ \\
\hline Duration of Membrane Rupture & $>4$ hours & $<4$ hours & $>4$ hours & $<4$ hours \\
\hline Mode of delivery & $\begin{array}{l}\text { Emergency } \\
\text { C-section }\end{array}$ & Vaginal & $\begin{array}{l}\text { Emergency } \\
\text { C-section }\end{array}$ & Vaginal \\
\hline Birth weight & 4,240 & 3,160 & 3,260 & 2,750 \\
\hline
\end{tabular}

${ }^{1} \mathrm{ZDV}=$ zidovudine $;{ }^{2} \mathrm{AR} ; \mathrm{T}=$ antiretroviral. 
those newly infected are commonly of lower socioeconomic status and have acquired HIV by heterosexual routes [1]. At study entry, most of our patients denied classical risk factors for HIV acquisition and were asymptomatic; most were diagnosed at the same time their child was diagnosed with HIV, following referral to our Institution, or because of HIV screening during prenatal care. Universal HIV testing of pregnant women has not yet been fully implemented in Brazil; in Rio de Janeiro city, that has a HIV prevalence of $1 \%$ in pregnant women [23] and an average of 100,000 live births per year, current estimates are that $45 \%$ of the total HIV positive pregnant women are identified and receive ZDV prophylaxis. Such problems are common in the developing world [24], and/or efforts must be made to implement strategies, for example rapid tests, at the first prenatal visit and/ or during labor for those who were not tested previously in order to offer the benefits of ARV treatment to mothers and infants [25].

Few pregnant women infected by HIV in our cohort had signs and/or symptoms attributable to HIV infection, and, in 73 cases, 3TC and/or other anti-retrovirals were added to the 076 regimen because of low $\mathrm{CD}_{4}$ and/or high viral load at entry. This may explain why viral load or immune status at entry were not significantly associated with HIV transmission. We were unable to measure viral load and $\mathrm{CD}_{4}$ levels near labor in our cohort, which is likely an optimal time to measure response to therapy initiated in the prenatal period, and to assess factors associated with intra-partum transmission. Prior to the availability of combined therapy, many studies showed an association of HIV transmission from a mother with advanced disease to her infant [21, 22, 26, 27]; however, a recent study conducted in women with more advanced disease revealed that ZDV alone worked, even with these women (PACTG 185) [28]. None of the 12 patients who presented with opportunistic infections during pregnancy transmitted HIV to their infants; all of them received combined anti-retroviral therapy (mostly AZT plus 3TC), and 6 received protease inhibitors; this regimen was well-tolerated during pregnancy [14].
Compliance with the integrated multidisciplinary prenatal program provided to our cohort was excellent with only $6.3 \%$ (11/176) non-adherent; $88.2 \%$ reported compliance with all three components of 076 . The intra-partum component was the part most commonly missed, usually because patients arrived late in labor and delivered shortly thereafter. Because of this problem, we now counsel our patients to take 3 (100 mg) tablets of ZDV po when they leave home to go to the maternity unit, so they will have a loading dose of ZDV in their system at the time of delivery, with levels that have been reported similar to that of iv administration as described in the CDC/Thai study [9].

Regarding obstetrical factors, mother to infant transmission of HIV was more frequent in women whose duration of membrane rupture was greater than 4 hours (although there were very few infected infants in our study). Most of our patients had less that 4 hours duration of membrane rupture $(88.1 \%)$. We believe this success is the result of health education training provided to the medical staff of the public maternity unit. In addition, we taught our patients the importance of going to the maternity if they noticed rupture of membranes or had onset of uterine cramps; they were provided with written instructions explaining obstetrical risk factors for HIV vertical transmission and outlining the dose of iv ZDV during labor and for the newborn [19].

In developing countries, it is important for patients to understand the obstetrical risk factors associated with HIV transmission, and to reinforce that short duration of membrane rupture is associated with less transmission from mother to infant. Our goal is to have all HIV-infected pregnant women delivering with less than 4 hours of membrane rupture, since longer duration has been proven to be a risk factor for HIV vertical transmission in a number of worldwide studies [22, 27]. There was no clear association with the mode of delivery and HIV infection in our cohort, although no HIV transmission was seen in 38 patients who underwent elective Csection. Because the morbidity and mortality associated with $\mathrm{C}$-sections in developing countries is high, the risks and benefits of this procedure must be carefully considered; we believe elective C- 
section should be reserved for those women with high viral load near labor or for those who present late in delivery without previous ZDV treatment [29-32].

We attribute the fact that we had no complication associated with $\mathrm{C}$-sections in our 91 patients (combined elective and emergency) to routine antibiotic prophylaxis. However, localized skin infections of the abdominal wall were frequently seen, and usually resolved with local wound care [33].

We detected no differences in transmission when factoring in birth weight or premature birth (<37 weeks) as risk factors, in contrast to what was found in other studies [22, 27]. All newborns received the postpartum component of intra-partum zidovudine treatment, and only 4/145 received it for less than the recommended 6 weeks. As part of our patient education program, mothers were taught about the storage administration and of the syrup; and were advised of their infant's necessary follow-up for toxicity monitoring and dose adjustment assessment. Breast-feeding was strongly discouraged and formula was provided to all women to be used for the HIV-exposed newborns. However, despite this education program, two mothers breastfed their children in the first week of life due to socio-cultural factors; such pressures to breastfeed may be an especially difficult problem for HIV infected women in developing countries, where breast feeding is the cultural norm [34].

Concern has been raised about using formula in developing countries, and whether such anintervention is safe. In our study, only 3 babies were admitted to the emergency unit because of diarrhea and dehydration (2 of them wereHIV infected). Thus, provision of safealternatives to breast feeding and adequate education on hygienic preparation of formulahas proven to be a successful strategy without significant gastrointestinal complications or adverse nutritional consequences to the baby [13].

Vertical transmission of HIV-1 is a multifactorial and dynamic process; the prevalence of risk factors reported to be associated with transmission has varied among different populations studied. In natural history cohorts, prior to the availability of intra-partum zidovudine treatment, transmission rates were reported as $14 \%$ to $30 \%$ in the industrialized world and $25 \%$ to $40 \%$ in developing countries [27]. Two Brazilian cohort studies of HIV infected pregnant women, conducted prior to the availability of the zidovudine treatment protocol, have been conducted: first, a multicenter, retrospective cohort in São Paulo state and, second, a prospective study in Riode Janeiro city showed an overall HIV transmission rate of $16 \%$ (CI:13-20\%) and 39.8\%, respectively. In both studies, transmission was higher in a setting where mothers had advanced disease and infants were breastfed $[21,26]$. Although the findings in our study were not statistically significant because of the small numbers of infected children, there was a trend towards less transmission in women with higher $\mathrm{CD}_{4}$ and lower viral load, similar to that reported in other cohorts [35-38]. Since the availability of treatment for HIV infected pregnant women, vertical transmission rates have dramatically decreased in developed countries; today the vertical transmission rate of HIV-1 in Europe and in the United States is reported as 5\% with ZDV prophylaxis alone, and with combined therapy including elective cesarean section, $2 \%$ or less [39]. There was also a significant difference concerning compliance with use of intra-partum antiretrovirals in transmitting mothers when compared to non-transmitting $(\mathrm{p}=0.05)$ and a trend to greater transmission with prolonged rupture of membranes ( $\mathrm{p}=0.08)$, according to other studies.

Shorter courses of ZDV during pregnancy and oral administration during labor without the postpartum component in a non-breastfed population, resulted in a reduction of $51 \%$ in the HIV vertical transmission rate in Thailand [9]; many other modified ZDV regimens with and without 3TC and other agents (ie., Nevirapine) were carried out in developing countries of Africa and Asia, in efforts to find effective and less costly prophylactic regimens [40]. Such regimens, while more costeffective, have not resulted in decreased transmission to the extent seen in our study cohort. Brazil, in its unique situation as a transitional country with attributes of both the developed and developing world, has the advantage of ZDV and other anti-retrovirals being provided by the government, which is uncommon in many developing countries. However, we have some of the same problems as other developing countries, including the lack of adequate public health training and an inadequate health care infrastructure for the implementation of comprehensive prenatal HIV 
screening and routine obstetrical care, as found in North America and Europe. Thus, the successful prevention of vertically transmitted pediatric HIV infection in Brazil will continue to be a challenge requiring national and regionspecific solutions to problems of healthcare and infrastructure development. Our program of integrated care for HIV positive mothers and their infants, linked to our programs of health care education which teaches strategies to prevent perinatal transmission, has resulted in the important result of a rate of perinatal HIV transmission similar to that achieved in developed countries. Such efforts must be continually reinforced in Rio de Janeiro, at other institutions caring for women and children at risk for HIV, and in other areas of Brazil in order to achieve effective control of the AIDS epidemic in children. This goal requires continued educational programs, the development of strategies for routine HIV testing of all pregnant women, and the recognition that comprehensive prenatal care coupled to the provision of antiretroviral therapy and formula to the mother and her infant, are necessary prerequisites for a successful strategy to eliminate perinatally acquired HIV infection in Brazil.

\section{Acknowledgements}

The authors thank the Japanese Foundation for AIDS Prevention for providing part of the financial support for buying laboratory kits and formula, and the Fogarty International Training Program for supporting development and distribution of educational materials by our Program, and staff training.

\section{References}

1. Brasil, Ministério da Saúde, Divisão de DST/AIDS: AIDSBoletim Epidemiológico, ano XIII, 1, dezembro/1999 a junho/2000.

2. Connor E.M., Sperling R.S., Gelber R., et al. Reduction of maternal-infant transmission of human immunodeficiency virus type I with zidovudine treatment. Pediatric AIDS Clinical Trials Group Protocol 076 Study Group. NEngl J Med 1994;331:1173-80.

3. Simpson J.B., Shapiro E.D., Andiman W.A. Reduction in the risk of vertical transmission of HIV 1 associated with treatment of pregnant women with orally administered zidovudine alone. J Acquir Immune Defic Syndr 1997; 14:145-52.
4. Mayaux M.J., Teglas J.P., Mandelbrot L., et al. Acceptability and impact of zidovudine for prevention of mother to child human immunodeficiency virus 1 transmission in France. J Pediatr 1997; 131:857-62.

5. Wade N.A., Birkhead G.S., Warren B.L., et al. Abbreviated regimens of zidovudine prophylaxis and perinatal transmission of the human immunodeficency virus. $\mathrm{N}$ Engl J Med 1998;339:1409-14.

6. Turner B.J., Newschaffer C.J., Zhang D., et al. Translating Clinical Trial Results into Practice: the effect of an AIDS clinical trial on prescribed antiretroviral therapy for HIV infected pregnant women. Ann Intern Med 1999;130:978-86.

7. Van Dyke R.B., Korber B.T., Popek E., et al. The Ariel Project: a prospective cohort study of maternal-child transmission of human immunodeficiency virus type 1 in the era of maternal antiretroviral therapy. J Infect Dis 1999; 179:319-28.

8. Cohen J. Bringing AZT to poor countries. Science 1995;269:264-66.

9. Vuthipongse P., et al.: Administration of Zidovudine during late pregnancy and delivery to prevent perinatal HIV transmission - Thailand, 1996-1998. MMWR 1998;47:151-4.

10. Lurie P., Wolfe S.M. Unethical trials of interventions to reduce perinatal transmission of human immundeficiency virus in developing countries. N Engl J Med 1997;337:836-46.

11. Mauskopf J., Paul J.E., Wichman D.S., et al. Economic impact of treatment of HIV positive pregnant women and their newborns with zidovudine. JAMA 1996; $276: 132-8$.

12. Soderlund N., Zwi K., Kinghorn A., Gray G. Prevention of vertical transmission of HIV: analysis of cost effectiveness of options available in South Africa. BMJ 1999;318:1650-6.

13. Nogueira S.A., Garcia M.F., Mercadante R., et al.: Avoidance of breastfeeding by HIV infected woman: strategy of a multiprofessional team in a developing country (abstract.n.12404). In: Program and abstracts of the XII International Conference on AIDS, Geneve 1998.p.94.

14. Brasil, Ministério da Saúde, Coordenação Nacional DST/ AIDS: Guia de tratamento clínico da Infecção pelo HIV em Adultos e Adolescentes, capítulo: Recomendações para redução da transmissão vertical do HIV, Brasília, 1998, $19-20$.

15. Centers for Diseases Control and Prevention: Public Health Service Task Force recommendations for the use of antiretroviral drugs in pregnant women infected with HIV -1 for maternal health and for reducing perinatal HIV 1 transmission in the United States. MMWR 1998;47(RR-2):1-30. 
16. Centers for Diseases Control and Prevention: 1994 Revised classification system for human immunodeficiency virus infection in children less than 13 years of age: Official Authorized Addenda: human virus infection codes and official guidelines for coding and reporting ICD-9-CM. MMWR 1994;43(RR-12).

17. Brasil, Ministério da Saúde, Secretaria de Políticas de Saúde, Coordenação Nacional de DST e AIDS: Infecção pelo HIV em criança - Guia de Tratamento Clínico. $2^{\mathrm{a}}$ ed, Brasilia, 1999, 23 p.

18. Steketee R.W., Abrams E.J., Thea D.M., et al. Early detection of Perinatal Human Immunodeficiency Virus (HIV) Type 1 Infection using HIV RNA Amplification and detection. J Infect Dis 1997; 175:707-11.

19. Lambert J.S., Nogueira S.A. Manual para o acompanhamento clínico ambulatorial da gestante infectada pelo HIV. $4^{\text {a }}$ ed. Rio de Janeiro, UFRJ, 2000, $110 \mathrm{p}$.

20. Lambert J.S., Nogueira S.A., Abreu T.F. Manual para o acompanhamento ambulatorial da criança infectada pelo HIV . $2^{\mathrm{a}}$ ed. Rio de Janeiro, UFRJ, 1999, 111 p.

21. Tess B.H., Rodrigues L., Newell M.L., et al. Breastfeeding, genetic, obstetric and other risk factors associated with mother to child transmission of HIV -1 in São Paulo State, Brazil. AIDS 1998;12:513-9.

22. Landesman S.H., Kalish L.A., Burns D.N., et al. Obstetrical factors and the transmission of Human Immunodeficiency virus type I from mother to child. N Engl J Med_1996;334:1617-23.

23. Stanjbock D.N., Rodrigues R., Santos A.L., et al: Prevalence of HIV, syphilis and hepatitis B infection in 1000 pregnant women from an inner city hospital of Rio de Janeiro. In Abstracts of the II Conference on Global Strategy for the Prevention of HIV Transmission from Mothers to Infant. Montreal, 1999, p.128.

24. Nouati R. Strategies in Africa in Conference on Global Strategy for the Prevention of HIV transmission from Mothers to Infant, edited by Martin N \& Ammann A. Washington, 1997, p.133-4.

25. Minkoff H., O'Sullivan M.J. The case of the rapid testing during labor. JAMA 1998; 279:1743-44.

26. Rubini N.P.M., Arabe J., Cordovil A.V.D.P., et al. HIV 1 vertical transmission in Rio de Janeiro: rate and risk factors. In :Abstracts of the XI International Conference on AIDS, Vancouver 1996, vol.1, p.363.

27. Mofenson L.M. Epidemiology and determinants of vertical HIV transmission. Seminars on Pediatric Infectious Diseases 1994;5:252-65.

28. Stiehm E.R., Lambert J.S., Mofenson L.M., et al. Efficacy of zidovudine and hyperimmune HIV immunoglobulin for reducing perinatal disease, results of Pediatric AIDS Clinical Trials Group Protocol 185. J Infect Dis 1999; 179:567-75.
29. Hudson C.N. Elective caesarean section for prevention of vertical transmission of HIV 1 infection. Lancet 1999;353:1030-1.

30. European mode of delivery collaboration: elective caesarean-section versus vaginal delivery in prevention of vertical HIV 1 transmission: a randomised trial. Lancet 1999;353:1035-9.

31. Read J., and The International Perinatal HIV group. The mode of delivery and the risk of vertical transmission of Human Immunodeficiency Virus Type 1 - a metaanalysis of 15 prospective cohort studies. New Engl J Med 1999;340:977-87.

32. Mandelbrot L., Le Chenadec J., Berrebi A., et al. Perinatal HIV-1 transmission: interaction between zidovudine prophylaxis and mode of delivery in the French Perinatal Cohort. JAMA 1998;280:55-60.

33. Semprini A.E., Castagna C., Ravizza S.F., et al. The incidence of complications after caesarean section in 156 HIV-positive women. AIDS 1995;9:913-7.

34. John G. Current status of breastfeeding studies on prevention of HIV transmission in Conference on Global Strategy for the Prevention of HIV Transmission from Mothers to Infant, edited by Martin N and Ammann A. Washington, 1997:51-7.

35. Sperling R.S., Shapiro D.E., Coombs R.W., et al.: Maternal viral load, zidovudine treatment and the risk of transmission of human immunodeficiency virus type 1 from mother to infant. N. Engl. J Med 1996;335:1621-9.

36. Mofenson L.M., Lambert J.S., Stiehm E.R., et al. Risk factors for perinatal transmission of human immunodeficiency virus Type I in women treated with zidovudine. N Engl J Med 1999;341:385-93.

37. Garcia P.M., Kalish L.A., Pitt J., et al.: Maternal levels of plasma human immunodeficiency virus type 1 RNA and the risk of perinatal transmission. N Eng J Med 1999;341:394-402.

38. Burns D.N., Landesman S., Wright D.J., et al. Influence of other maternal variables on the relationship between maternal virus load and mother to infant transmission of human immunodeficency virus type 1 . J Infect Dis 1997; 175:1206-10.

39. Blanche S., Rouzioux C., Mandelbrot L., et al. Zidovudinelamivudine for the prevention of mother to child HIV 1 transmission. In: Abstracts of the 6 th. Conference on Retrovirus and Opportunistic Infections. Chicago, 1999.

40. Mofenson L., McIntyre J. Advances and research directions in the prevention of mother to child HIV 1 transmission. Lancet 2000;355: 2237-44. 